Antony Joseph Porcino, BSc, ${ }^{1}$ and Marja J. Verhoef $\mathrm{PhD}^{2}$

${ }^{I}$ CAMEO (Complementary Medicine Education and Outcomes) Project, BC Cancer Agency, Vancouver, BC, Canada and ${ }^{2}$ Professor and Canada Research Chair in Complementary Medicine, Department of Community Health Sciences, University of Calgary, Calgary, AB, Canada

Mixed methods research is the integration of quantitative and qualitative components in a research project. Whether you are reading or designing a mixed methods research project, it is important to be familiar with both qualitative and quantitative research methods and the specific purposes for which they are brought together in a study: triangulation, complementarity, expansion, initiation, or development. In addition, decisions need to be made about the sequencing and the priority or importance of each qualitative and quantitative component relative to the other components, and the point or points at which the various qualitative and quantitative components will be integrated.

Mixed methods research is increasingly being recognized for its ability to bring multiple points of view to a research project, taking advantage of the strengths of each of the quantitative and qualitative components to explain or resolve complex phenomena or results. This ability becomes critical when complex healing systems such as therapeutic massage are being studied. Complex healing systems may have multiple physiologic effects, often reflected in changes throughout the patient's body. Additionally, the patient's experience of the treatment may be an important outcome.

KEYWORDS: Mixed methods, research design, experimental designs, methodology

Mixed methods researchers need to carefully consider both why they are integrating quantitative and qualitative research in their studies and how they are going to accomplish this integration in practice.

- Plano Clark and Creswell(1) (p. 251)

\section{WHAT IS MIXED METHODS RESEARCH?}

The most common definition of mixed methods research focuses on the combination of quantitative and qualitative research within one study ${ }^{(2,3)}$. The terms "mixed methods" and "mixed methods research" have come to be widely used since 2000 , although discussion and application of this approach under many names goes back to the mid-1960s $\mathrm{s}^{(2,4)}$. Some terms for mixed methods research, such as "combined methods" or "multi-method studies," continue to be used ${ }^{(4-6)}$.

Mixed methods research requires an understanding both of quantitative and qualitative research methods and of their underlying theories and perspectives or paradigms (ways of viewing the world) and also an appreciation of how new knowledge may become available when the two methods are brought together within a single study ${ }^{(2-4,7)}$.

The purpose of this article is

- to introduce manual therapists to mixed methods research and its relevance, and

- to discuss common features and ways in which quantitative and qualitative methods can be combined.

Several examples are provided to illustrate mixed methods research. We also explore why mixed methods may be particularly important within therapeutic massage research.

\section{REVIEW OF QUANTITATIVE AND QUALITATIVE RESEARCH}

Broadly speaking, scientific research involves systematically and methodically following a recognized research protocol to answer a specific question. The question can be focused on an idea, a process, or a theory about the origin or manifestation of a subject of interest. That focusing occurs within a research paradigm, a way of perceiving the world through which a researcher conceives of and studies his or her research question(s). The two predominant research paradigms are positivist/post-positivist and constructivist.

The positivist/post-positivist paradigm takes the perspective that an underlying objective unchanging truth (the subject of the research) can be found or approximated through careful observation and measurement ${ }^{(7,8)}$. The paradigm assumes that the 
researcher is value-free (has no opinions or biases regarding the subject of the research) and is therefore able to measure the subject without bias or expectation while researching the subject ${ }^{(8)}$. Research based within this paradigm usually uses quantitative methods.

When viewing a given phenomenon from a constructivist paradigm, there is no single underlying truth, but rather there are as many experiences of the phenomenon as there are people experiencing it. Understanding how people have constructed their perception or perceptions of the phenomenon thus provides insight into the nature and contextual environment of that phenomenon ${ }^{(7-12)}$. There is no assumption that the researcher is bias-free, but rather that the researcher will make clear how personal beliefs and experiences may influence the research process and the construction of the results. This paradigm is often also associated with the related interpretivist paradigm and the advocacy/critical theory/participatory paradigm in which advocacy for change is associated with knowledge translation of the results. Research based within this group of closely-related paradigms usually uses qualitative methods ${ }^{(7,8,13)}$.

\section{Quantitative Research}

Quantitative methods measure the difference between the before and the after states of a research object of interest or take a "snapshot" (such as a survey questionnaire) to quantify the state at that moment of the object being studied. Quantitative analysis of the measurements usually involve statistics, and the study results are usually also communicated using statistics. Quantitative methods can be found in all forms of science in which measurement is involved. Here, we focus on the research methods of health and health services.
Data collection for quantitative methods generally falls into two categories: survey "instruments" or "tools" (special-purpose questionnaires) and biological measurements. There are many outcome questionnaires, all carefully developed and researched so that their strengths and weaknesses are known. The Outcomes Database (http://www.outcomesdatabase.org) lists many that may be useful for studying complementary and alternative medicine (CAM). Biological measurements include levels of chemical markers that can be obtained from body fluids such as saliva, blood, or urine, from movement measurements such as range of motion, and from other measurements such as weight, density, temperature, or shape. All these forms of data result in numbers that can be statistically analyzed.

There are many quantitative research designs. Small-scale projects may use research designs such as case studies and case series, and also single-subject research designs and pilot projects, both of which use methods from larger studies, but apply them to only one person or a small group of people. Larger studies can take many forms, the most common being summarized in Table 1.

A number of articles and books have described the value of quantitative research to the therapeutic massage profession ${ }^{(11,14,15)}$. Much therapeutic massage research enquiry is quantitative, and usually of a trial design, such as in the following possible research scenarios:

- To test whether, compared with current standard treatment, a standardized cross-fiber friction protocol can reduce carpal tunnel syndrome pain (trial)

- To compare the mobility effects in chronic lower back pain of a whole-body massage routine with a lower back massage routine (trial)

TABLE 1. Common Quantitative Research Methods

\begin{tabular}{|c|c|c|}
\hline Survey methods & Questionnaire & Data collected summarized and analyzed using statistics. \\
\hline \multirow{3}{*}{$\begin{array}{l}\text { Experimental or } \\
\text { trial methods }\end{array}$} & Interviews and documents & $\begin{array}{l}\text { Words, phrases, images, ideas in the interviews and documents counted and analyzed us- } \\
\text { ing statistics. Documents can be written materials, images, and video, among others. }\end{array}$ \\
\hline & $\begin{array}{l}\text { Variants of the randomized } \\
\text { controlled trial }(\mathrm{RCT})\end{array}$ & $\begin{array}{l}\text { An outcome of interest is measured in a group of people, a treatment applied to some of the } \\
\text { people, the outcome re-measured and then compared between the two groups of people. }\end{array}$ \\
\hline & Quasi-experimental & $\begin{array}{l}\text { Similar to the RCT, but one or more factors of the RCT cannot be applied. For example, } \\
\text { randomization may not be ethical if treatment must be withheld. }\end{array}$ \\
\hline \multirow{3}{*}{ Cohort } & Natural & $\begin{array}{l}\text { An external force on a population (for example a new government policy or an environ- } \\
\text { mental disaster) creates a change of interest that can be measured. }\end{array}$ \\
\hline & Prospective & $\begin{array}{l}\text { Follow a group of people over time and take measurements at predetermined times. } \\
\text { There is usually a comparison group. Prospective studies may also involve trials. }\end{array}$ \\
\hline & Case-control & $\begin{array}{l}\text { A retrospective study in which people with a medical outcome of interest are compared } \\
\text { with similar people without that outcome, and their histories are explored to identify pos- } \\
\text { sible factors leading to the outcome. }\end{array}$ \\
\hline \multirow[t]{2}{*}{$\begin{array}{l}\text { Research } \\
\text { compilation }\end{array}$} & Systematic review & $\begin{array}{l}\text { Using carefully defined selection criteria, results from multiple studies are analyzed } \\
\text { and compared. }\end{array}$ \\
\hline & Meta-analysis & Similar to a systematic review, but the data from multiple studies are pooled and reanalyzed. \\
\hline
\end{tabular}


- To measure pre- and post-treatment serotonin levels and compare them with other biomarkers for depression to help elucidate the mechanism that mediates the reduction of depression after massage (trial)

- To determine the optimal time for administration of hand or foot massage to reduce nausea after a cancer chemotherapy administration by following groups of people (cohorts) who have received massage administered at different time points after chemotherapy and by then comparing the degree of nausea for each cohort (cohort trial)

\section{Qualitative Research}

Well-developed in the fields of nursing, education, and psychology, qualitative research is being increasingly appreciated for its value in the health disciplines ${ }^{(16)}$. Unlike quantitative approaches, which produce numerical measurements, qualitative research develops a contextual understanding of the research subject from the multiple points of view captured in the data. Data can be visual (images), spoken ["aural" (recorded or live)], or written (documents). The most common form is recorded interviews that are then transcribed for analysis and notes taken about what was seen or observed. The data are analyzed by looking for clusters of meaning across the entire collection. Depending on the purpose and the methods used, the analysis yields results that range from simple description of a subject, to basic interpretation of a subject, or to theory or abstraction of contextual data(10,16,17). The results are shared in written descriptions and summaries supported by examples taken from the data sources. Table 2 summarizes several common methods in qualitative research.

Researchers have described the value of qualitative research to the therapeutic massage profession ${ }^{(11,18)}$.
Qualitative massage-based research questions such as these could be of interest to researchers:

- What process is used by manual therapists to develop palpatory competence? (grounded theory)

- How do successful male massage therapists overcome perceived gender barriers in the massage profession? (critical theory)

- What value do occasional and regular therapeutic massage users ascribe to their treatments? (phenomenology)

- How do therapeutic massage practitioners conceive of and use evidence in the context of their practice? (qualitative description)

\section{MIXED METHODS RESEARCH}

As mentioned at the beginning, mixed methods research brings together quantitative and qualitative methods within a single study. While theoretically it can involve any combination of the above methods, the qualitative methods used are often more simple, like the description methods.

This section will begin with current examples of therapeutic massage mixed methods projects. The next sub-sections will detail the purpose and structural design considerations of mixed methods research. This section will conclude with two brief historical sections, to provide context to the development of mixed methods: clarifying the name; and moving beyond qualitative versus quantitative debates using the framework of pragmatism.

\section{Mixed Method Research Project Examples}

Searches for studies using "mixed methods" or "combined methods" and "massage" in PubMed, Ovid, and the Massage Therapy Foundation database did not locate any studies. Additional

TABLE 2. Common Qualitative Research Methods

\begin{tabular}{|c|c|c|}
\hline \multirow[t]{6}{*}{ Constructivist } & Ethnography & Explore shared perceptions within a social group. \\
\hline & Grounded theory & Develop theory about a process or experience. \\
\hline & Phenomenology & $\begin{array}{l}\text { Explore lived experience. Branches of phenomenology are used to explore specific social } \\
\text { constructs such as language and texts. }\end{array}$ \\
\hline & Case study & $\begin{array}{l}\text { Unlike quantitative case studies, these case studies use all forms of data to explore and } \\
\text { fully understand a single case or incident of interest. }\end{array}$ \\
\hline & Qualitative description & $\begin{array}{l}\text { Explore and present a simple, straightforward understanding of the data without attempt- } \\
\text { ing to interpret findings. }\end{array}$ \\
\hline & Interpretive description & Like qualitative description, but looks for meaning within the developing results. \\
\hline \multirow[t]{3}{*}{ Activist } & Critical theory & Explores issues from minority perspectives to gain insight into social structure. \\
\hline & Action research & $\begin{array}{l}\text { Similar to critical theory, but with a focus on applying the results to foster change as part } \\
\text { of the research process. }\end{array}$ \\
\hline & Participatory action research & Similar to action research, but the participants are involved in applying the results. \\
\hline
\end{tabular}


searching revealed three studies. To expand the examples available, we have included as well the Brazier study and our own project, which is currently being written up for publication, We are introducing these examples of mixed methods research in therapeutic massage here. We will return to them again for analysis of their design details and the studies' results. The lack of studies appears to suggest the use of mixed methods research for therapeutic massage is very limited, but likely simply represents a lack of familiarity with mixed methods research. As we will point out, this approach may be the best for capturing the essence of therapeutic massage interventions.

- Menard-Like a Burden Has Been Lifted: Massage Therapy for People with Breast Cancer ${ }^{(19)}$

Project description: A poster presentation describing early results of research still under way in patients in the Washington, DC, area of the United States. The quantitative results were captured using questionnaires. Comments written on the questionnaires provided qualitative detail about the context of the questionnaire answers. A focus group to explore some results or issues was pending at the time of the poster presentation.

- Paterson et al.-Evaluating a Massage Therapy Training and Treatment Programme in a Remote Aboriginal Community ${ }^{(20)}$

Project description: Quantitative questionnaires were used to monitor outcomes of massage treatments on patients of massage therapist trainees. Qualitative interviews explored the individual (patient) and community effects of providing a massage therapy training program for Aboriginals in Hopevale, Australia.

- Porcino et al.-A Mixed Methods Study Examining the Influence of Training on Long-Term Practice of Manual Therapists (in preparation)

Project description: The quantitative component documented the training and practice demographics of therapeutic massage practitioners in Alberta, Canada. Practitioners with training in multiple therapies were interviewed, exploring the many influences of multiple training on daily practice.

- Price-Body-Oriented Therapy in Recovery from Child Sexual Abuse: An Efficacy Study ${ }^{(21)}$

Project description: Patients from a locale in Washington State, United States, were randomized to either a body-oriented therapy treatment approach or a massage therapy-only routine. Outcomes were measured using standardized questionnaires. One questionnaire had openended questions in response to which participants could write descriptive answers.

- Brazier et al.-Evaluating a Yogic Breathing and Meditation Intervention for Individuals Living with HIV/AIDS ${ }^{(22)}$
Project description: In this study, participants in Vancouver, British Columbia, Canada, who received the intervention exhibited negative effects according to the quantitative measures. Interviews were planned to gain an understanding of the effects and value of the program from participants.

\section{Purpose}

Based in part on Morse (2005) ${ }^{(23)}$, Sandelowski cautions us to watch for inappropriate reasons used to justify a mixed methods approach ${ }^{(24)}$.

Mixed-methods research should never be used [when the purpose is based on] the misguided assumptions that more is better, that it is the fashionable thing to do, or ... that qualitative research is incomplete without quantitative research. (p. 254, emphasis added)

In 1989, Greene, Caracelli, and Graham published a study ${ }^{(3)}$ in which they identified five primary theoretical purposes for employing mixed method research designs (Table 3 ). The five categoriestriangulation, complementarity, expansion, development, and initiation - are common in today's mixed methods literature.

In 2006, Bryman published a similar review ${ }^{(26)}$. He recognized sixteen different reasons for studies to be undertaken, but acknowledged that those categories simply provided a more nuanced understanding of the five categories outlined by Greene et al.

Taking the time to consider the category of a project's purpose will provide insight into what the project is meant, and not meant, to achieve. To that end, Plano Clark and Creswell exhort researchers to be methodical, starting at the planning stage ${ }^{(1)}$ :

Mixed methods researchers need to carefully consider both why they are integrating quantitative and qualitative research in their studies and how they are going to accomplish this integration in practice. (p. 251)

In studying the purposes of mixed methods projects, Bryman and the Greene group both found many mismatches between the stated goals and purposes of published studies and what was actually done in those studies ${ }^{(3,26)}$. Although the mismatching may partly reflect a lack of readily available mixed methods guidance at the time of the studies, it likely also reflects how a research project may become more complex than originally planned. Surprising results may encourage a change to a mixed methods design to help understand the results, as in the Brazier study. In preplanned mixed methods projects, results from one component may change a planned research component or analysis. 
Table 3. Purposes of Mixing Methods in a Research Study

\begin{tabular}{|c|c|c|}
\hline Purpose & Description & Examples \\
\hline Triangulation & $\begin{array}{l}\text { Using two or more methods to measure the same thing so } \\
\text { that different angles or perspectives (convergence, corrobo- } \\
\text { ration) give weight to the interpretation of a phenomenon } \\
\text { or result in a specific way }{ }^{(3,8,25)} \text {. }\end{array}$ & $\begin{array}{l}\text { Including open-ended questions on a questionnaire, ask- } \\
\text { ing for written information about a question or answer. } \\
\text { Example projects: Menard; Price }\end{array}$ \\
\hline Complementarity & $\begin{array}{l}\text { Using results of one research method to elaborate, illus- } \\
\text { trate, clarify, or enhance the results of another or to achieve } \\
\text { a more full understanding of a phenomenon or phenomena } \\
\text { by using the different methods to study different aspects }{ }^{(3)} \text {. }\end{array}$ & $\begin{array}{l}\text { Pursuing a qualitative study (interviews) to gain an un- } \\
\text { derstanding about the context of an unusual result from a } \\
\text { clinical intervention. } \\
\text { Example project: Porcino et al. }\end{array}$ \\
\hline Expansion & $\begin{array}{l}\text { Similar to complementarity, but with a broader project } \\
\text { scope and the components of the phenomenon or } \\
\text { phenomena being less closely linked, often using different } \\
\left.\text { methods "for different inquiry components" (p. } 259^{(3)}\right) \text {. } \\
\text { Expansion may therefore be more exploratory in how the } \\
\text { research components bring the various results together. }\end{array}$ & $\begin{array}{l}\text { Using a clinical intervention and interviews about the in- } \\
\text { tervention to understand the full value of an intervention } \\
\text { from a broader perspective than just the clinical effects. } \\
\text { Example project: Paterson et al. }\end{array}$ \\
\hline Development & $\begin{array}{l}\text { Using sequential methods in which the results of the first } \\
\text { process are used in implementing or refining the second } \\
\text { research process }{ }^{(3)} \text {. }\end{array}$ & $\begin{array}{l}\text { Using qualitative interviews as the first step in choosing } \\
\text { appropriate language for a questionnaire on a socially } \\
\text { relevant but sensitive subject. }\end{array}$ \\
\hline Initiation & $\begin{array}{l}\text { Carefully analyzing the results of the quantitative and } \\
\text { qualitative components to find areas of concordance and } \\
\text { discordance, and using those juxtapositions to arrive at } \\
\text { new insight and understanding of a phenomenon }{ }^{(3)} \text {. }\end{array}$ & $\begin{array}{l}\text { In contrasting interviews and clinical results during a } \\
\text { study, a new understanding may be revealed. } \\
\text { Example project: Brazier et al. }\end{array}$ \\
\hline
\end{tabular}

\section{Project Structure}

\section{Sequencing}

Perceiving the project purpose may take a while and can be aided by considering the structural components of mixed methods projects. The first structural consideration is whether the quantitative and qualitative components occur sequentially or concurrently $(3,4,7,27)$. Studies that require the results of one section to begin the next section use sequential designs; the research components in concurrent designs can be run independently of one another. Several writers describe sequencing as occurring only in time-for example, the descriptions by Onwuegbuzie and Johnson of the conditions of concurrent and sequential designs (p. 53) (28). However, our study on the effects of training for therapeutic massage treatment decision-making is conceptually concurrent (the research into one component was not required to inform the second component), but we ran it sequentially for two reasons:

- Our letter of interview invitation went out with the questionnaire.

- We wanted the option of using the interviews to clarify any unexpected questionnaire results.

Larger studies may have multiple sequential components within which there may be single (quantitative or qualitative) or concurrent research projects.

\section{Priority}

Studies may not focus equally on the results of both the quantitative and qualitative components ${ }^{(3,4,7,27)}$.
Often, especially in sequential studies, quantitative data are used to help explain the qualitative results, or vice versa. The choice of the predominate method type depends on the framing of the research question. The notation of UPPER CASE (predominant component) and lower case (subordinate component), combined with an arrow (sequence) or plus sign (concurrent) is now commonly used to represent the priority and the sequencing of the qualitative (qual) or quantitative (quan) component. Table 4 shows how the notation is used for the various possible priority combinations. This succinct method of notation was originally presented by Janice Morse in $1991^{(27)}$.

Any project can be designed using a single priority combination, or it may involve multiple research stages that can cycle or shift between these combinations or "go in waves"'(7,24). The research question or questions and the theoretical framework used to construct the questions will indicate whether the overall project has a quantitative or qualitative priority and theoretic perspective, and whether sequential or concurrent components, or both, will be needed to answer the questions. Teddlie and Tashakkori point out in their article on the complexity of mixed methods designs that, sometimes, the priority or weighting of a study will shift later in the research process ${ }^{(29)}$.

\section{Point of Integration}

The progression of a research study can be visualized as a sequence of project steps; integration can occur at any of these sequence points. At its most basic, this sequence is 
TABle 4. Priority Diagrams in Mixed Methods per Morse's notation(27)

\begin{tabular}{|c|c|c|}
\hline Priority diagram & Explanation & Examples \\
\hline \multicolumn{3}{|l|}{ Sequential options } \\
\hline $\begin{array}{l}\text { QUAN } \rightarrow \text { qual } \\
\text { QUAL } \rightarrow \text { quan }\end{array}$ & $\begin{array}{l}\text { The first component is the predominant part of } \\
\text { the study, and the secondary component is done } \\
\text { afterward. }\end{array}$ & $\begin{array}{l}\text { QUAN } \rightarrow \text { qual: Using qualitative interviews to explore } \\
\text { an unusual clinical result (often a form of triangulation). } \\
\text { Example projects: Brazier et al.; Menard }\end{array}$ \\
\hline $\begin{array}{l}\text { quan } \rightarrow \text { QUAL } \\
\text { qual } \rightarrow \text { QUAN }\end{array}$ & $\begin{array}{l}\text { The predominant part of the study is done after } \\
\text { the secondary component has been completed. }\end{array}$ & $\begin{array}{l}\text { qual } \rightarrow \text { QUAN: Using interviews to develop a } \\
\text { questionnaire; collecting demographics and clinical data } \\
\text { about a population from which interviewees will be } \\
\text { drawn. }\end{array}$ \\
\hline \multicolumn{3}{|l|}{ Concurrent options } \\
\hline $\begin{array}{l}\text { QUAN + qual } \\
\text { QUAL + quan }\end{array}$ & $\begin{array}{l}\text { The secondary component often resembles } \\
\text { a nested process within the primary research } \\
\text { component, occurring at the same time, either } \\
\text { with the same sample or with different samples. }\end{array}$ & $\begin{array}{l}\text { QUAN + qual: Including spaces on questionnaires where } \\
\text { respondents are encouraged to describe or explain their } \\
\text { answers in more detail. } \\
\text { Example projects: Price; Menard }\end{array}$ \\
\hline QUAN + QUAL & $\begin{array}{l}\text { Both components are considered equally } \\
\text { important and are often run independently. } \\
\text { Integration of the components begins in the } \\
\text { analysis stage. }\end{array}$ & $\begin{array}{l}\text { QUAN + QUAL: For example, assessing the outcomes } \\
\text { of therapeutic massage treatments by new students, } \\
\text { interviewing community members about the impact of } \\
\text { the new training program in their remote community. } \\
\text { Example projects: Paterson et al.; Porcino et al. }\end{array}$ \\
\hline
\end{tabular}

Research question $\rightarrow$ Data collection $\rightarrow$ Data analysis $\rightarrow$ Interpretation

Numerous authors have commented on these points of integration $^{(2,4,7,26)}$.

Fully integrated studies begin with conceptualization of the study, because issues of design, research question development, and literature review should also be developed from a mixed methods perspective. Different purposes, sequencing, and priority will encourage integration at different points of the research sequence ${ }^{(4,7,26)}$. Projects with development, complementarity, and triangulation purposes may begin integration at the data collection stage (such as from comments on questionnaires). All project purposes easily accommodate integration at the interpretation stage. Concurrent studies are more able to integrate at any point along the sequence; sequential studies begin integration when the results or interpretation from the first component are used to begin the next.

Closely linked with sequencing, priority may affect how integration occurs: Is a transformation of quantitative data to qualitative data, or qualitative interviews into a questionnaire, being done at the point of data collection or of analysis ${ }^{(30)}$ ? Is the lower-priority component meant to help the analysis or interpretation of the higher-priority component? Studies that compare, contrast, develop, or explore how the data from each research component enhances the understanding of another component can integrate at more than one point $\mathrm{t}^{(2,4,7,26)}$.

\section{Putting these ideas together: results from the examples}

The research components of purpose, sequencing, priority, and integration will now be identified within the mixed methods research examples previously listed. For each study we have listed the sequencing, priority, and purpose in the first boxes of each table. The integration is described as part of the studies' results.

- Menard-Like a Burden Has Been Lifted: Massage Therapy for People with Breast Cancer ${ }^{(19)}$

Multistage sequence

QUAN + qual (nested open-ended questions on a questionnaire)

QUAN $\rightarrow$ qual (same questionnaire, followed by a focus group)

Purpose appears to be primarily for triangulation.

What Was Learned: Menard's quantitative results indicated that clients "reported statistically significant reductions in symptom severity" from having received massage. The qualitative component provided some clinically relevant and persuasive material. The title "Like a Burden Has Been Lifted" was drawn directly from that source and points to a significant quality-of-life factor that is often secondary to the cancer outcome focuses 
of radiation, surgery, and chemotherapy. (Integration: Design, Data Collection, Interpretation)

- Paterson et al.-Evaluating a Massage Therapy Training and Treatment Programme in a Remote Aboriginal Community ${ }^{(20)}$

QUAN + QUAL (questionnaires and interviews)

Purpose appears to be expansive.

What Was Learned: The quantitative component indicated direct benefit of the massage therapy component, but the qualitative results indicated that there would be value in pursing the ongoing availability of massage therapy training and provision in Hopevale and similar remote Aboriginal communities, because it "interconnected with the people of Hopevale on three levels: with individuals; the community; and the wider geographic, cultural and political context"' (pp. 165-166). Revealing and comprehending this broad framework shows the power of mixed methods research. (Integration: Design, Interpretation)

- Porcino et al.-A Mixed Methods Study Examining the Influence of Training on Long-Term Practice of Manual Therapists (in preparation)

QUAN + QUAL (questionnaires and interviews)

Purpose appears to use a complementarity perspective.

What Was Learned: More than 90\% of questionnaire respondents were trained in multiple therapies, with little similarity in training patterns. The interviews documented that, in normal practice, treatment decisions are made throughout practice and draw on all the clinical skills, training, and experience that the practitioner has amassed. Integrating the two at analysis and interpretation highlights some of the difficulties in assuming that a standardized treatment occurs during research, even with explicit treatment protocols. (Integration: Design, Interpretation)

- Price-Body-Oriented Therapy in Recovery from Child Sexual Abuse: An Efficacy Study ${ }^{(21)}$

QUAN + qual (qualitative, open-ended questions on standardized questionnaires)

Purpose appears to be primarily for triangulation, but results also show some complementarity.

What Was Learned: Patients were randomized to either a body-oriented therapy approach or a massage therapy-only routine. At the end, although both groups showed similar positive outcomes, the qualitative component indicated that "the groups differed on perceived experience of the intervention and its influence on therapeutic recovery" (p. 46) and therefore on the value of the intervention. (Integration: Design, Data collection, Interpretation)

- Brazier et al.-Evaluating a Yogic Breathing and Meditation Intervention for Individuals Living with HIV/AIDS ${ }^{(22)}$

QUAN $\rightarrow$ qual (questionnaires and interviews) Purpose appears to be initiation (explore unexpected findings).

What Was Learned: In this study, the participants who received the intervention exhibited negative and stressful effects according to the quantitative measures. Yet those effects were fully explained and understood to be positive experiences through the qualitative component. (The process of developing and feeling greater self-awareness is not always a comfortable or easy one.) "Using combined methods in this study enhanced the ability to capture adequate information about the phenomena under study as well as the validity of data interpretation. In particular ... it was learned that meaningful change for the participants did not appear to be captured in the chosen outcome measures, and the qualitative findings were necessary ... to assist with an appropriate interpretation of quantitative findings" (p. 194). (Integration: Design, Interpretation)

- Questionnaire development (additional generic example)

qual $\rightarrow$ QUAN

Purpose is for development (of a questionnaire).

How It Is Applied: Qualitative studies are often used to help refine a questionnaire so as to increase questionnaire response and accuracy. Studies achieve this result by ensuring that the language in the questionnaire is both relevant to, and best understood by, the population being studied. Qualitative studies may also be used to decide which issues are most important to address through a questionnaire sent to a larger population. The qualitative development process could include one or more of the following techniques, possibly with several iterations as the questionnaire is refined:

- Interviews about the most effective and appropriate language or about specific topics of interest

- Written or verbal critiques of the questions

- Interviews about the experience of filling out the questionnaire 
- Listening to representative respondents speak their thoughts as they complete the questionnaire

This process would be followed by a quantitative process of implementing the questionnaire. (Integration: Design, Data analysis)

\section{SIGNIFICANT HISTORICAL ISSUES IN MIXED METHODS}

The subsections that follow provide brief introductions to two areas of considerable and ongoing debate in mixed methods research. Reference to these issues may still appear in mixed methods articles.

\section{Naming This Research Approach}

The generally accepted mixed methods definition is "qualitative and quantitative components in a single study." Therefore, what is a project called that uses only multiple quantitative or only multiple qualitative methods? On that point, consensus has not yet been achieved.

Another issue is what to call a study process that shows no integration of its quantitative and qualitative research components. Some researchers may use terms such as "parallel methods" or "multiple methods studies." Verhoef and Vanderheyden recommend using "combined methods" when integration of the quantitative and qualitative components occurs in most or all components of a research project ${ }^{(31)}$. This article uses "mixed methods" for all degrees of integration of quantitative and qualitative methods within a single study.

The important point is that every mixed methods study should carefully explain its definition of mixed methods by describing how the mixing or combining is achieved.

\section{Successfully Combining Qualitative and Quantitative Research}

The most contentious theoretical discussions during the development of the mixed methods research framework have addressed the question of whether post-positivist and constructivist research can coexist within a study or whether those approaches are incommensurate - that is, a researcher cannot use both paradigms simultaneously.

From a research-in-practice perspective, most mixed methods researchers accept that a researcher is not limited to using either quantitative or qualitative methods exclusively within a single study $(9,32)$. This acceptance leads to paradigm relativism - "the use of whatever philosophical and/or methodological approach works for the particular research problem under study"(2) (p. 9). This perspective is often called the pragmatic approach or paradigm — or Pragmatism ${ }^{(13)}$. Researchers using a pragmatic approach comfortably encompass the integration of qualitative and quantitative methodology and meaning, using them to mutually augment one another, moving beyond the issue of whether the theoretic paradigms are incommensurate.

\section{MIXED METHODS SPECIFICALLY FOR THERAPEUTIC MASSAGE RESEARCH}

\section{Mixed Methods and CAM Research}

Therapeutic massage is a particularly appropriate area of research for mixed methods designs because, using such designs, researchers can examine more than one facet of an issue in the same study. For example, Menard was able both to assess the therapeutic reductions in severity of symptoms achieved by massage therapy treatment and to garner an understanding of the value of the treatment, beyond just symptom reduction, to the person. An expanded perspective of this kind is important when researching CAM therapies such as therapeutic massage, because the foundational premises of health and illness underlying these therapies often do not reflect a purely biomedical perspective.

Many CAM practices recognize and use components of the patient-practitioner relationship, including the ritual of the visit and the belief system of the patient, as an integrated part of the treatment and healing process ${ }^{(33)}$. As well, many CAM practices incorporate multiple methods of engagement - including physical touch or chemical input, psychological intervention, and accommodation to the patient's social context - and may even engage with realms that are not yet readily studied - such as energy work and spiritual dimensions ${ }^{(34,35)}$. Furthermore, all these engagements are often conceived of as an intricate whole on which any treatment will likely have both specific and generalized effects - hence, the designation "complex systems"(31). Much has been written on the complexities of CAM practices and, hence, of research into them ${ }^{(31,33,36-41)}$.

\section{Therapeutic Massage as a Complex CAM Healing System}

Therapeutic massage exemplifies many of the foregoing traits of a complex healing system. For example, describing the practice of therapeutic massage, Cassidy lists the following interrelated "goals of massage/bodywork therapy" (the goals ranging from physical to psychological and spiritual outcomes $^{(15)}$ (p. 3):

- Manipulate soft tissues (move body fluids, increase range of motion, promote structural change)

- Ease pain

- Promote relaxation 
- Balance and remove blockages in the flow of energy

- Provide comfort (physical and emotional alike)

- Support self-realization

The profession also exhibits other traits of complex healing systems. Few practitioners are identically trained, and practitioner experience affects treatment skills and perceptions, resulting in treatments that are likely personalized to what is found in a client's tissues while treatment $\operatorname{occurs}^{(15, a)}$.

As well, the receiver of therapeutic massage experiences multiple effects that can be difficult to tease out:

- The ritual of the treatment visit

- Expectations from past experience or from learning acquired through various media

- Hopes for the treatment

- The physical experiences during treatment

- The practitioner-patient relationship

Finally, complicating measurement, the exact mechanism of action for most manual therapies is not known, but appears to be mediated through a variety of routes, including

- changes to the recipient's psychological states,

- nerve function and response,

- connective tissue states, and

- changes in biochemical levels, used as markers of physiologic change ${ }^{(15,42)}$.

Changes mediated by these routes, and many of the receiver's perceptions (such as state of relaxation, depression, anxiety, and so on), are seldom limited only to the tissues manipulated ${ }^{(14,43)}$. Many of the foregoing goals, treatment routes, and physical and psychological responses are interrelated. Therefore, treatment focused on one goal or one tissue area will also likely have effects elsewhere.

\section{Accommodating Therapeutic Massage to Classical Research Designs}

The goal of much of clinical research design in therapeutic massage is to verify the value of a treatment, usually isolating a single effect of interest for a particular treatment goal, such as the four examples given earlier at the end of the "Quantitative Research" subsection. However, because of the nature of therapeutic massage as a complex system, standard research designs may have some shortcomings:

- Placebo: In clinical trials, a placebo treatment (no actual therapeutic content) is typically used

a Porcino et al. A Mixed Methods Study Examining the Influence of Training on Long-Term Practice of Manual Therapists. In preparation. to provide a baseline measurement that accounts for some of the nonspecific treatment effects, such as those mediated by the receiver's perceptions. Sham treatments have been proposed as a placebo in manually applied treatments ${ }^{(40)}$; however, for complex systems research, sham-controlled results may not produce strong evidence, especially when the full mechanism of action is not understood (is the correct sham being created?) and when a sham massage may still have physiologic effects (and may even be detected as a sham rather than a real treatment massage), destroying its ability to function as a placebo.

- Practitioner effects: Standard trials assume consistency in treatment application, which may be difficult to achieve in therapeutic massage because of practitioner variability. As well, in daily practice, treatment is constantly personalized. The use of multiple methods to monitor a range of treatment inputs (from practitioner, patient, and environmental sources) and treatment results (biologic, mental, emotional, and spiritual) may help to capture or resolve important components of this practice research issue.

- Nonspecific effects: When the results of a therapy are likely produced by one or more nonspecific treatment effects, choosing the appropriate outcome measures may be difficult. Mixed methods may help both to chose outcomes and to capture a broad range of relevant outcomes in the physical and psychological realms alike.

- Patient effects: The values or beliefs of the patient and how they relate to physical or physiologic outcomes may be more easily and fully captured using a mixed methods approach, because the two components being related are likely qualitative and quantitative data.

Thus the possibilities opened by mixed methods research should be carefully considered.

In summary, then, three important advantages of mixed methods design in the case of therapeutic massage research are

- the ability to capture a broad range of outcomes, including those relevant to the patient, that may not be easily captured by quantitative measurement tools alone (for example, the Menard ${ }^{(19)}$ and Price studies ${ }^{(21)}$ ), including the ability to guide the adaptation of quantitative tools to better accommodate complex outcomes.

- the ability to provide perspective on results that may be unexpected, may not be understood, or may not be clear on meaning (for example, the Brazier et al. study ${ }^{(22)}$ ).

- the ability to enhance the exploration and perception of ideas and outcomes by using multiple perspectives simultaneously, thus synergistically (total effect is greater than the sum of the parts) 
revealing understanding that could not be gleaned from a mono-paradigm approach (for example, Paterson et al. ${ }^{(20)}$ and Porcino et al. ${ }^{\mathrm{b}}$ studies).

\section{CONCLUSIONS}

Mixed methods research involves understanding and applying knowledge of quantitative and qualitative research components alike. It is therefore more complex than using either of those approaches on their own, involving more work, increased resources and time, and complexity in design, implementation, and evaluation. In planning or reporting a mixed methods study, the purpose, sequence, priority, and point or points of integration should be clearly identified. The rewards of mixed methods research come from surmounting the limitations imposed by the use of a single research method and paradigm framework, thereby gleaning a broader and more insightful perspective that can be helpful in understanding complex phenomena.

The fact that therapeutic massage research currently shows few mixed methods examples does not mean that mixed methods lack value to the field of therapeutic massage research. As has been shown here, mixed methods have great value in the field of therapeutic massage research, and the potential of the approach should be considered more often. By using the full gamut of research methods, researchers can achieve a greater understanding of the significance and reality of the practice of therapeutic massage.

\section{CONFLICT OF INTEREST NOTIFICATION}

The authors are not aware of any conflicts of interest or potential conflicts of interest regarding the material in this manuscript.

\section{COPYRIGHT}

Published under the CreativeCommons Attribution-NonCommercial-NoDerivs 3.0 License.

\section{REFERENCES}

1. Plano Clark VL, Creswell JW. The Mixed Methods Reader. Thousand Oaks, CA: Sage Publications; 2008.

2. Introduction to mixed method and mixed model studies in the social and behavioral sciences. In: Tashakkori A, Teddlie C. Mixed Methodology: Combining Qualitative and Quantitative Approaches. Thousand Oaks, CA: Sage Publications; 1998: 3-19.

b Porcino et al. A Mixed Methods Study Examining the Influence of Training on Long-Term Practice of Manual Therapists. In preparation.
3. Greene JC, Caracelli VJ, Graham WF. Toward a conceptual framework for mixed-method evaluation designs. Educ Eval Policy Anal 1989; 11(3): 255-274.

4. Creswell JW, Plano Clark VL, Guttmann ML, Hanson EE. Advanced mixed methods research designs. In: Tashakkori A, Teddlie C, eds. Handbook of Mixed Methods in Social and Behavioral Research. Thousand Oaks, CA: Sage Publications; 2003: 209-240.

5. Scott CM, Verhoef MJ, Hilsden RJ. Inflammatory bowel disease patients' decisions to use complementary therapies: links to existing models of care. Complement Ther Med 2003; 11(1): 22-27.

6. Wathen CN. Alternatives to hormone replacement therapy: a multi-method study of women's experiences. Complement Ther Med 2006; 14(3): 185-192.

7. Creswell JW. Research Design: Qualitative, Quantitative, and Mixed Methods Approaches. 2nd ed. Thousand Oaks, CA: Sage Publications; 2003.

8. Bowling A. Research Methods in Health : Investigating Health and Health Services. 2nd ed. Maidenhead, U.K.: Open University Press; 2007.

9. Pope C, Mays N. Reaching the parts other methods cannot reach: an introduction to qualitative methods in health and health services research. BMJ 1995; 311(6996): 42-45.

10. Creswell JW. Qualitative Inquiry and Research Design: Choosing Among Five Traditions. 2nd ed. Thousand Oaks, CA: Sage Publications; 2007.

11. Hymel GM. Research Methods for Massage and Holistic Therapies. Mosby's Massage Career Development Series. St. Louis, MO: Elsevier Mosby; 2006.

12. Maiterud K. Qualitative research: standards, challenges, and guidelines. Lancet 2001; 358(9280): 483-488.

13. Morgan DL. Paradigms lost and pragmatism regained: methodological implications of combining qualitative and quantitative methods. J Mix Methods Res 2007; 1(1): 48-76.

14. Menard MB. Methodological issues in the design and conduct of massage therapy research. In: Rich GJ, ed. Massage Therapy: The Evidence for Practice. Toronto, ON: Mosby; 2002: 27-41.

15. Cassidy C. Methodological issues in investigations of massage/ bodywork therapy. Evanston, IL: American Massage Therapy Association Foundation; 2002.

16. Thorne S. Interpretive Description. Vol. 2 of Developing Qualitative Inquiry. Walnut Creek, CA: Left Coast Press; 2008.

17. Sandelowski M. Whatever happened to qualitative description? Res Nurs Health 2000; 23(4): 334-340.

18. Kania A, Porcino A, Verhoef M. Value of qualitative research in the study of massage therapy. Int $J$ Ther Massage Bodyw 2008; 1(2): 6-10.

19. Menard MB. Like a burden has been lifted: massage therapy for people with breast cancer. Massage Therapy Foundation website. http://www.massagetherapyfoundation.org/postersession. html\#Like a burden has been lifted: Massage Therapy for People with Breast Cancer. Published 2009. Updated n.d. Accessed February 18, 2010.

20. Paterson C, Vindigni D, Polus B, Browell T, Edgecombe G. Evaluating a massage therapy training and treatment programme in a remote Aboriginal community. Complement Ther Clin Pract 2008; 14(3): 158-167. 
21. Price C. Body-oriented therapy in recovery from child sexual abuse: an efficacy study. Altern Ther Health Med 2005; 11(5): 46-57.

22. Brazier A, Mulkins A, Verhoef M. Evaluating a yogic breathing and meditation intervention for individuals living with HIV/ AIDS. Am J Health Promot 2006; 20(3): 192-195.

23. Morse JM. What is qualitative research? Qual Health Res 2005; 15(7): 859-860.

24. Sandelowski M. Combining qualitative and quantitative sampling, data collection, and analysis techniques in mixed-method studies. Res Nurs Health 2000; 23(3): 246-255.

25. Jick TD. Mixing qualitative and quantitative methods: triangulation in action. Adm Sci Q 1979; 24(4): 602-611.

26. Bryman A. Integrating quantitative and qualitative research: how is it done? Qual Res 2006; 6(1): 97-113.

27. Morse JM. Approaches to qualitative-quantitative methodological triangulation. Nurs Res 1991; 40(2): 120-123.

28. Onwuegbuzie AJ, Johnson RB. The validity issue in mixed research. Res Sch 2006; 13(1): 48-63.

29. Teddlie C, Tashakkori A. A general typology of research designs featuring mixed methods. Res Sch 2006; 13(1): 12-28.

30. Sandelowski M, Voils CI, Knafl G. On quantitizing. J Mix Methods Res 2009; 3(3): 208-222.

31. Verhoef M, Vanderheyden L. Combining qualitative methods and RCTs in CAM intervention research. In: Adams J, ed. Researching Complementary and Alternative Medicine. Abingdon, U.K.: Routledge; 2007: 72-86.

32. Giddings LS, Grant BM. Mixed methods research for the novice researcher. Contemp Nurse 2006; 23(1): 3-11.

33. Trotter G. Culture, ritual, and errors of repudiation: some implications for the assessment of alternative medical traditions. Altern Ther Health Med 2000; 6(4): 62-68.

34. Tataryn DJ. Paradigms of health and disease: a framework for classifying and understanding complementary and alternative medicine. J Altern Complement Med 2002; 8(6): 877-892.

35. Jones $\mathrm{CH}$. The spectrum of therapeutic influences and integrative health care: classifying health care practices by mode of therapeutic action. J Altern Complement Med 2005; 11(5): 937-944.
36. Verhoef MJ, Lewith G, Ritenbaugh C, Boon H, Fleishman $\mathrm{S}$, Leis A. Complementary and alternative medicine whole systems research: beyond identification of inadequacies of the RCT. Complement Ther Med 2005; 13(3): 206-212.

37. Bell IR, Koithan M. Models for the study of whole systems. Integr Cancer Ther 2006; 5(4): 293-307.

38. Need for innovative designs in research on CAM and conventional medicine. In: Committee on the Use of Complementary and Alternative Medicine by the American Public, Board on Health Promotion and Disease Prevention. Complementary and Alternative Medicine in the United States. Washington, DC: The National Academies Press; 2005: 108-128.

39. Fønnebø V, Grimsgaard S, Walach H, Ritenbaugh C, Norheim $\mathrm{AJ}$, MacPherson $\mathrm{H}$, et al. Researching complementary and alternative treatments - the gatekeepers are not at home. BMC Med Res Methodol 2007; 7: 7.

40. Hammerschlag R, Zwickey H. Evidence-based complementary and alternative medicine: back to basics. J Altern Complement Med 2006; 12(4): 349-350.

41. Richardson J. Evidence-based complementary medicine: rigor, relevance, and the swampy lowlands. J Altern Complement Med 2002; 8(3): 221-223.

42. Rogers SL. Massage therapy following spinal cord injury. In: Rich GJ, ed. Massage Therapy: The Evidence for Practice. Toronto, ON: Mosby; 2002: 105-130.

43. Field TM. Massage therapy for immune disorders. In: Rich GJ, ed. Massage Therapy: The Evidence for Practice. Toronto, ON: Mosby; 2002: 47-56.

Corresponding author: Antony Joseph Porcino, CAMEO Project, BC Cancer Agency, 912-750 West Broadway, Vancouver, British Columbia V5Z 1H1 Canada.

E-mail: ajporcin@ucalgary.ca 